\title{
A competing hydrogen bonding pattern to yield thermo- thickening supramolecular polymer
}

\author{
Virgile Ayzac, ${ }^{[a]}$ Quentin Sallembien, ${ }^{[a]}$ Matthieu Raynal, ${ }^{[a]}$ Benjamin Isare, ${ }^{[a]}$ Jacques Jestin, ${ }^{[b]}$ and \\ Laurent Bouteiller ${ }^{*[a]}$
}

\begin{abstract}
We show that introduction of competing interactions in the design of a supramolecular polymer (SP) allows to create pathway complexity. Ester-bisureas contain both a strong bisurea sticker that is responsible for the build-up of long rod-like objects by hydrogen bonding and ester groups that can interfere with this main pattern in a subtle way. Spectroscopic (FTIR and CD), calorimetric (DSC) and scattering (SANS) techniques show that such ester-bisureas actually self-assemble into three competing rod-like SPS. The previously unreported low temperature $S P$ is stabilized by hydrogen bonds between the interfering ester groups and the urea moieties. It is also characterized by a weak macroscopic alignment of the rods. The other structures form isotropic dispersions of rods that are stabilized by the more classical urea-urea hydrogen bonding pattern. The transition from the low temperature structure to the next structure occurs reversibly by heating and is accompanied by an increase in viscosity, a rare feature for solutions in hydrocarbons.
\end{abstract}

SPs are chain-like assemblies of self-complementary monomers with unique properties and applications..$^{[1]-[4]}$ The reversible but directional non-covalent interactions responsible for their selfassembly provide tunability and responsiveness ${ }^{[5]}$ to various stimuli. This has contributed to the development of innovative catalysts, ${ }^{[6],[7]}$ fluorescent systems, ${ }^{[8],[9]}$ self-healing materials ${ }^{[10],[11]}$ and gels ${ }^{[12],[13]}$ among other potential applications. One fascinating consequence of the dynamic character of supramolecular assemblies is the capability of molecular building blocks to assemble into distinct thermodynamically or kinetically stable nanostructures. ${ }^{[14]} \mathrm{A}$ number of studies describe the possibility of selecting one of these nanostructures by carefully controlling the conditions of aggregation i.e. time, ${ }^{[15]-[18]}$ concentration, ${ }^{[19]}$ temperature, ${ }^{[20]}$ solvent ${ }^{[21]-[25]}$ and diffusion ${ }^{[26]}$ or by tuning the nature of the monomer. ${ }^{[27]-[29]}$ This pathway complexity in the aggregation ability of the monomers is usually revealed by spectroscopic techniques which identify the structural differences in the assemblies at the nano or mesoscale (e.g. kinetics of aggregation, helicity, stacking mode, conformation). ${ }^{[30],[31]}$ However, a change in the properties of the supramolecular assemblies at the macroscale has been reported for very few cases. ${ }^{[20],[32]}$ In fact, the properties of SPs can be considerably diversified when they form in competition with other assemblies. Indeed, pathway complexity can be responsible for unusual behaviors such as a self-assembly that is triggered by dilution, ${ }^{[19]}$

[a] Dr. V. Ayzac, Q. Sallembien, Dr. M. Raynal, Dr. B. Isare, Dr. L. Bouteiller

Sorbonne Université, CNRS, Institut Parisien de Chimie Moléculaire,

Equipe Chimie des Polymères

F-75005 Paris, France

E-mail: laurent.bouteiller@sorbonne-universite.fr

[b] Dr. J. Jestin

Laboratoire Léon Brillouin, UMR 12 CNRS-CEA

91191 Gif-sur-Yvette Cedex, France or by both increasing or decreasing the temperature. ${ }^{[33]}$ In particular, when two competing SPs can assemble from the same monomer, ${ }^{[25]}$ the transition between the two structures can result in noticeable macroscopic property changes. ${ }^{[20]}$

The introduction of competing interactions in the design of a supramolecular assembly is a logical approach to create pathway complexity. In practice, this can be done through solvents, ${ }^{[21],[34],[35]}$ and additives ${ }^{[19],[33],[36],[37]}$ or by introducing functional groups that can interfere with the main sticker. Often, this latter approach will weaken the main assembly, ${ }^{[38],[39]}$ but it can also lead to a new structure with a competitive thermodynamic stability. ${ }^{[40]}$ Along this line, we previously reported that introducing an amino-ester synthon in the classical bisurea scaffold provides an efficient access to functionalized assemblies. ${ }^{[41],[42]}$ We later realized that the ester linkage that is introduced is not innocent: it allows a subtle modification of the hydrogen bond pattern and thus pathway complexity. Indeed, we now report that such ester-bisurea monomers self-assemble into three structurally different and competing SPs. All three structures are thermodynamically stable in their respective temperature range and can be accessed reversibly. Remarkably, this competition between supramolecular assemblies is responsible for a thermo-thickening effect, i.e. an increase of viscosity while temperature is raised.

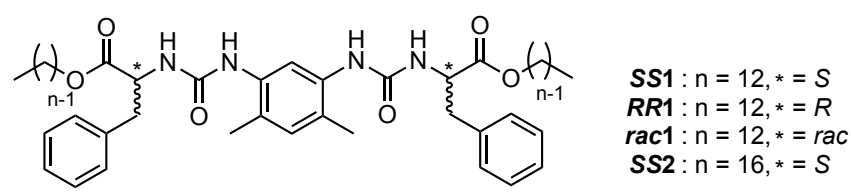

Scheme 1. Structure of ester-bisurea monomers.

Ester-bisurea SS1 (Scheme 1) is readily soluble in nonpolar solvents such as toluene where it forms viscous solutions. Infrared spectroscopy (FTIR) shows that it is fully hydrogen bonded up to $90^{\circ} \mathrm{C}$, with an $\mathrm{NH}$ stretching vibration lower than $3400 \mathrm{~cm}^{-1}$ (Figure 1). However, close inspection of these spectra reveals a complex thermal evolution, with three distinct spectral signatures. In the range from 60 to $90^{\circ} \mathrm{C}$, the urea $\mathrm{NH}$ are bonded (with broad maxima at 3330 and $3270 \mathrm{~cm}^{-1}$ ). We call this structure $\gamma$. It has previously been shown by small angle neutron scattering (SANS) to correspond to a long and rigid SP with a single monomer in the cross-section. ${ }^{[41]}$ In the range from 15 to $60^{\circ} \mathrm{C}$, the FTIR spectra are similar, but the $\mathrm{NH}$ vibration band is significantly less broadened. SANS analysis previously confirmed the structural transition and showed that this SP (called $\beta$ ) is also long and rigid, but contains 2 molecules in the cross-section, ${ }^{[41]}$ i.e. SP $\beta$ is twice thicker than $\gamma$. More interestingly, below $15^{\circ} \mathrm{C}$, a previously unreported band appears that corresponds to weakly bonded $\mathrm{NH}\left(3350 \mathrm{~cm}^{-1}\right)$. We call this unknown structure $\alpha$. In order to facilitate the characterization of this new structure, we tried and identified a solvent with low UV absorption and in which 
the $\alpha$ structure is stable at room temperature. Figures S1 and S2 show that the spectral signature of the 3 structures are exactly the same in methylcyclohexane $(\mathrm{MCH})$ as in toluene, but the transitions are shifted to higher temperatures. The stabilization of these hydrogen bonded assemblies in a less polarizable solvent is not surprising. Moreover, a calorimetric experiment (Figure 2) confirms the higher values of the transition temperatures in $\mathrm{MCH}$ and also shows that the transitions between each structure are fully reversible (i.e. there is no hysteresis).

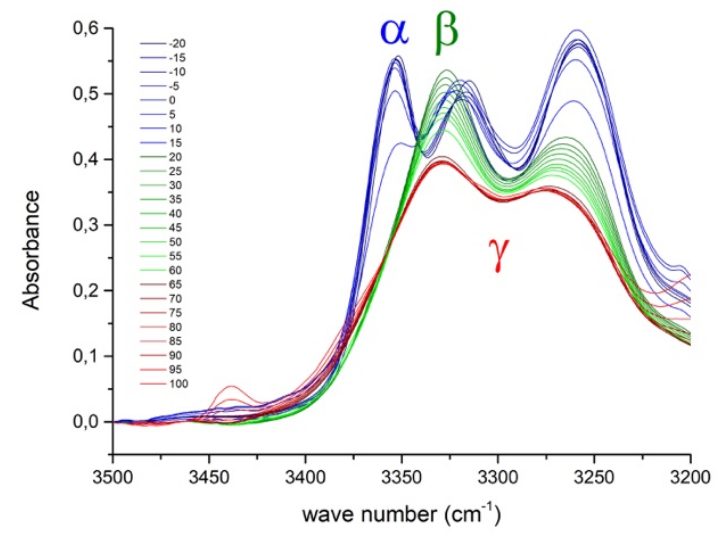

Figure 1. VT-FTIR spectra (zoom on the $\mathrm{NH}$ region) between -20 and $100^{\circ} \mathrm{C}$ (heating run, $1^{\circ} \mathrm{C} / \mathrm{min}$ ) for a $10 \mathrm{mM}$ solution of $\mathbf{S S 1}$ in toluene.

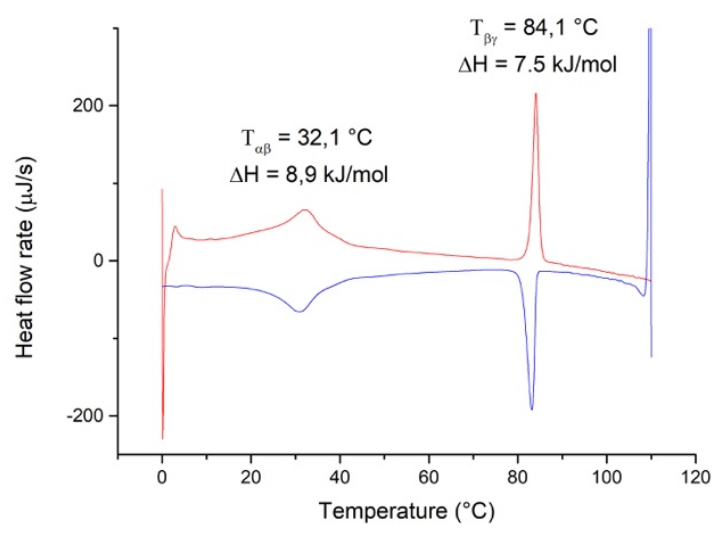

Figure 2. DSC data for a $10 \mathrm{mM}$ solution of $\mathbf{S S 1}$ in $\mathrm{MCH}\left(1^{\circ} \mathrm{C} / \mathrm{min}\right.$, heating (red) and cooling (blue)).

CD spectroscopy (Figure 3) confirms the presence of 3 supramolecular structures with the same transition temperatures as detected by FTIR and DSC. All 3 structures show a Cotton effect with a minimum at ca. $210 \mathrm{~nm}$ and a maximum at ca. 230 $\mathrm{nm}$, but different intensities. Moreover, a shoulder is visible at 217 $\mathrm{nm}$ for structure $\alpha$. Comparison with the spectrum in a solvent where $\mathbf{S S 1}$ is a monomer (THF) proves that all 3 structures display supramolecular chirality, but with subtle local molecular packing differences between them.
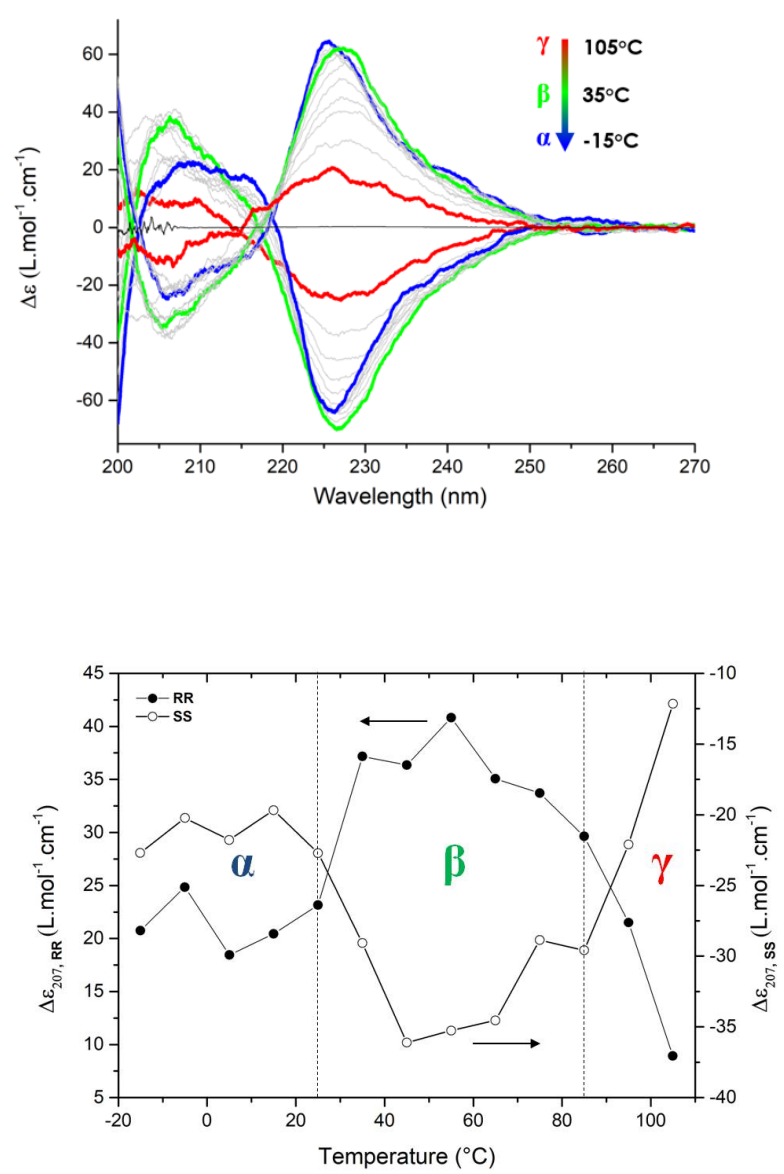

Figure 3. (top) VT-CD spectra between -15 and $105^{\circ} \mathrm{C}$ (cooling run, $1^{\circ} \mathrm{C} / \mathrm{min}$ ) for a $0.1 \mathrm{mM}$ solution of $\mathbf{S S 1}$ and $\boldsymbol{R} \boldsymbol{R} \mathbf{1}$ in $\mathrm{MCH}$ compared to the spectrum at $20^{\circ} \mathrm{C}$ for a $0.1 \mathrm{mM}$ solution of SS1 in THF. (bottom) Plot of the intensity at 207 $\mathrm{nm}$ versus temperature.

SANS experiments were then performed in the same solvent to characterize the shape of the assemblies. The most remarkable feature of the new structure $\alpha$ is that it yields an anisotropic scattering pattern (Figure 4a). This means that the supramolecular assemblies $\alpha$ display some long-range order and are macroscopically oriented. Heating to $66^{\circ} \mathrm{C}$ (Figure $4 \mathrm{~b}$, structure $\beta$ ) suppresses the anisotropy in the sample, but cooling down to $10^{\circ} \mathrm{C}$ (structure $\alpha$ ) again yields the initial anisotropic pattern. Azimuthal integration of the data (Figure S5) and fit according to Maier-Saupe theory yields an order parameter value of 0.062 . This low value allows to rule out the formation of a liquid crystal phase ${ }^{[43]}$ and actually indicates that the anisotropy is very weak. ${ }^{[4]}$ Integration of the data according to an isotropic averaging is plotted in Figure 4c. No difference can be seen between the two temperatures $\left(10\right.$ and $\left.66^{\circ} \mathrm{C}\right)$ indicating the global shape of assemblies $\alpha$ and $\beta$ are the same. Moreover, the scattered intensity can be fitted with the form factor for rigid rods 
with a circular cross-section of radius $18 \AA$ and a linear density that corresponds to 2.0 bisureas in the cross-section. Therefore, the subtle differences between structures $\alpha$ and $\beta$ that are revealed by FTIR and CD spectroscopies do not entail obvious changes in the shape of individual objects as probed by the SANS experiment in the accessible q range. However, the structural change is significant enough to translate into weak long-range order of the rod-like objects. This weak order may be the sign of a more rigid or longer structure for assemblies $\alpha$ than for assemblies $\beta$.

Coming back to the FTIR results (Figure 1), it is possible to extract some local structural information concerning assembly $\alpha$. First of all, the appearance at low temperature of a weakly bonded $\mathrm{NH}$ band $\left(3350 \mathrm{~cm}^{-1}\right)$ together with a bonded ester $\mathrm{C}=\mathrm{O}$ band $\left(1730 \mathrm{~cm}^{-1}\right.$, see Figure S1) means that some hydrogen bonds between $\mathrm{NH}$ and ester $\mathrm{C}=\mathrm{O}$ are formed: i.e. the classical hydrogen bonding pattern for ureas (Scheme S1b) is not operative for all ureas in structure $\alpha$. Since all NH groups are already involved in hydrogen bonding with urea $\mathrm{C}=\mathrm{O}$ at higher temperatures (structure $\beta$ ), it means that, at low temperatures (structure $\alpha$ ), either some three-centered bifurcated hydrogen bonds ${ }^{[45]-[47]}$ are formed (i.e. one $\mathrm{NH}$ is hydrogen bonded to both a urea $\mathrm{C}=\mathrm{O}$ and an ester $\mathrm{C}=\mathrm{O}$ ), or some hydrogen bonds to urea $\mathrm{C}=\mathrm{O}$ are broken and replaced by hydrogen bonds to ester $\mathrm{C}=\mathrm{O}$ (Scheme S1a). Both situations can actually occur either in an intramolecular ${ }^{[48],[49]}$ or an intermolecular fashion. Deconvolution of the ester $\mathrm{C}=\mathrm{O}$ band (Figure S3) shows that the free ester $\mathrm{C}=\mathrm{O}$ and bonded ester $\mathrm{C}=\mathrm{O}$ bands have about the same intensity, which means that roughly half of the ester groups are involved in hydrogen bonds in structure $\alpha$. Interestingly, this proportion has been probed over a large temperature range (from -70 to $20^{\circ} \mathrm{C}$ ) but it does not evolve.

The robustness of the $\alpha$ phase was then probed by slightly changing the bis-urea structure. Bis-ureas SS2 with a longer terminal alkyl chain (see Scheme1) also shows the spectroscopic signature of the $\alpha$ phase (Figures S7 and S8). In contrast, bisurea rac1 (i.e. the mixture of $S, S, R, R$ and $S, R$ isomers) does not display the spectroscopic signature of the $\alpha$ phase in the investigated temperature range (Figure S9). This last result implies that the stereochemical defects in the assemblies affect more strongly the $\alpha$ phase than the $\beta$ or $\gamma$ phases, i.e. the stereochemistry of the solute seems essential to the stability of the $\alpha$ phase.

Even if at this point the precise local modification between structures $\alpha$ and $\beta$ is not unraveled, it is of interest to probe its consequence on the properties of the assemblies. We first measured the viscosity of a dilute solution of SS1 in MCH (Figure S10). Remarkably, an increase of viscosity was measured when the temperature was increased through the transition from $\alpha$ to $\beta$, followed by the expected decrease from $\beta$ to $\gamma$. The initial increase is even more obvious if the relative viscosity is plotted (Figure 5) since the viscosity of the solvent is a decreasing function of temperature. Moreover, this unusual influence of temperature on viscosity occurs reversibly during heating or cooling (Figure S11). This result is remarkable since the viscosity of organic solutions usually decreases with temperature. Counter examples are known such as polymers dissolved in poor solvents, ${ }^{[50]}$ or supramolecular assemblies controlled by a ring-chain equilibrium. ${ }^{[51]}$ Still, a reversible thermo-thickening effect for a supramolecular assembly in a non-polar medium is particularly rare because the primary effect of an increase in temperature is to weaken supramolecular assemblies. Moreover, changing the solvent (dodecane) or the length of the alkyl chain of the monomer (ester-bisurea SS2) allows to tune the intensity of the thermothickening effect (Figure 5). As expected, rac1 displays a continuous decrease of the viscosity with the temperature, i.e. no thermo-thickening (Figure S10). This last result confirms the direct link between the spectroscopic signature of the $\alpha$ phase and the macroscopic consequence on viscosity.

The exact reason for the increase in viscosity is not known at present, but it is probably related to the loss of long-range interaction between the rods at the $\alpha$ to $\beta$ transition, as detected by SANS. In analogy with the viscosity increase from the nematic to isotropic phase of thermotropic liquid crystals, ${ }^{[52]}$ the increased disorder in the $\beta$ structure possibly leads to more entanglements and thus to a more viscous solution.

a)
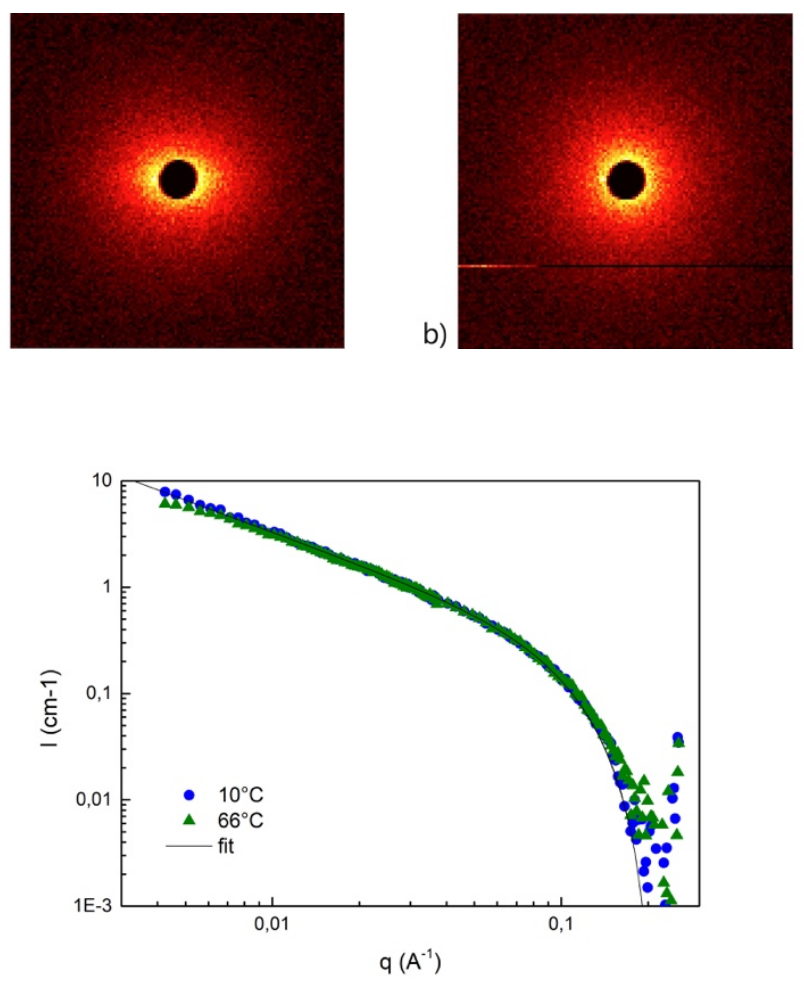

Figure 4. 2D SANS scattering pattern for a $6.9 \mathrm{mM}(5.9 \mathrm{~g} / \mathrm{L})$ solution of $S S 1$ in $\mathrm{MCH}-\mathrm{D}_{14}$ at $10^{\circ} \mathrm{C}$ (a) or $66^{\circ} \mathrm{C}$ (b). Corresponding 1D plots after isotropic averaging (c). The continuous line is a fit with the form factor of an infinitely long and rigid rod of homogeneous contrast, of circular cross-section (radius $18 \AA$ ) and of linear density $\left(0.43 \AA^{-1}\right)$ corresponding to 2 molecules in the cross-section. 


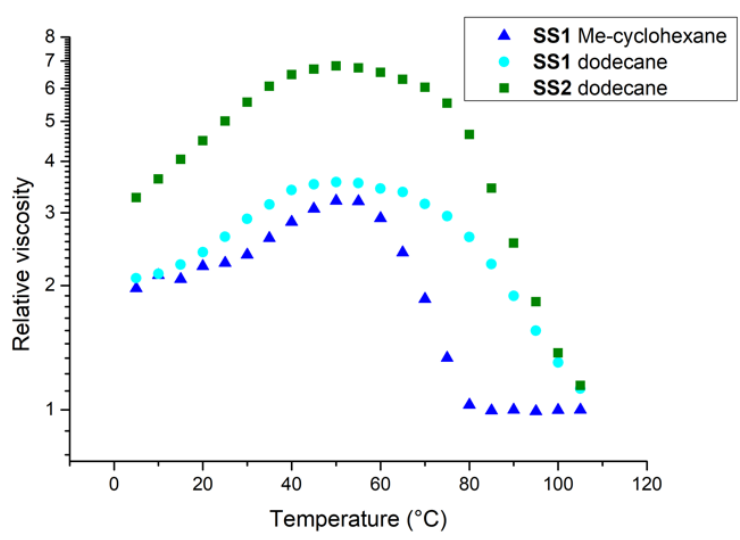

Figure 5. Relative viscosity $\left(\eta / \eta_{0}\right)$ versus temperature, for $0.1 \mathrm{mM}$ solutions of SS1 or SS2 in $\mathrm{MCH}$ or dodecane (heating scans).

Some bisureas with simple alkyl substituents are known to self-assemble into two competing rod-like SPs. ${ }^{[20]}$ Introducing hydrogen bond acceptors (such as ester groups) close to the urea moiety potentially allows other hydrogen bond patterns to form. Characterization by spectroscopic (FTIR and CD), calorimetric (DSC) and scattering (SANS) techniques provide a consistent proof that ester-bisurea $\mathbf{S S 1}$ actually self-assembles into three competing rod-like SP assemblies (see Table S1 for a summary). The previously unreported low temperature structure is stabilized at the molecular scale by hydrogen bonds between the interfering ester groups and the urea moieties. It is also characterized by a weak mesoscopic alignment of the rods. The other structures form isotropic dispersions of rods that are stabilized by the more classical urea-urea hydrogen bonding pattern at the molecular scale. The transition from the low temperature structure to the next structure occurs reversibly by heating and is interestingly accompanied by an increase in viscosity. This is an interesting example of the interplay that can occur between a subtle nanoscopic scale effect and macroscopic properties.

\section{Acknowledgements}

This work was supported by the French Agence Nationale de la Recherche (project ANR-12-BS08-0019 BalanceSupra). Nicolas Vanthuyne (iSm2, Marseille), Fabrice Mathevet (IPCM) and Ariane Suzzoni (KTH, School of Engineering Sciences, Stockholm) are acknowledged for chiral HPLC, POM and SANS analyses, respectively.

Keywords: self-assembly $\bullet$ hydrogen bonds $\bullet$ supramolecular polymer $\bullet$ pathway complexity $\bullet$ urea

[1] L. Brunsveld, B. J. B. Folmer, E. W. Meijer, R. P. Sijbesma, Chem. Rev. 2001, 101, 4071-4097.

[2] T. F. A. De Greef, M. M. J. Smulders, M. Wolffs, A. P. H. J. Schenning, R. P. Sijbesma, E. W. Meijer, Chem. Rev. 2009, 109, 56875754.

[3] L. Yang, X. Tan, Z. Wang, X. Zhang, Chem. Rev. 2015, 115,
7196-7239.

[4] B. Isare, S. Pensec, M. Raynal, Laurent. Bouteiller, C. R. Chim. 2016, 19, 148-156.

[5] X. Yan, F. Wang, B. Zheng, F. Huang, Chem. Soc. Rev. 2012, $41,6042-6065$.

[6] A. Desmarchelier, X. Caumes, M. Raynal, A. Vidal-Ferran, P. W. N. M. van Leeuwen, L. Bouteiller, J. Am. Chem. Soc. 2016, 138, 4908-4916.

[7] J. M. Zimbron, X. Caumes, Y. Li, C. M. Thomas, M. Raynal, L. Bouteiller, Angew. Chem., Int. Ed. 2017, 56, 14016-14019.

[8] F. J. M. Hoeben, P. Jonkheijm, E. W. Meijer, A. P. H. J.

Schenning, Chem. Rev. 2005, 105, 1491-1546.

[9] S. S. Babu, V. K. Praveen, Ayyappanpillai. Ajayaghosh, Chem. Rev. 2014, 114, 1973-2129.

[10] F. Herbst, D. Döhler, P. Michael, W. H. Binder, Macromol.

Rapid Commun. 2013, 34, 203-220.

[11] L. R. Hart, J. L. Harries, B. W. Greenland, H. M. Colquhoun, W. Hayes, Polym. Chem. 2013, 4, 4860-4870.

[12] A. R. Hirst, B. Escuder, J. F. Miravet, D. K. Smith, Angew.

Chem., Int. Ed. 2008, 47, 8002-8018.

[13] A. Dawn, T. Shiraki, S.-I. Haraguchi, S.-I. Tamaru, Seiji.

Shinkai, Chem. - Asian J. 2011, 6, 266-282.

[14] B. Rybtchinski, ACS Nano 2011, 5, 6791-6818.

[15] Y. Yan, J. Huang, B. Z. Tang, Chem Commun. 2016, 52, 11870 11884.

[16] A. Sorrenti, J. Leira-Iglesias, A. J. Markvoort, T. F. A. de Greef, T. M. Hermans, Chem. Soc. Rev. 2017, 46, 5476-5490.

[17] S. Ogi, T. Fukui, M. L. Jue, M. Takeuchi, K. Sugiyasu, Angew. Chem. 2014, 53, 14363-14367.

[18] A. Aliprandi, M. Mauro, L. De Cola, Nat. Chem. 2016, 8, 10-15.

[19] F. Helmich, C. C. Lee, M. M. L. Nieuwenhuizen, J. C. Gielen, P.

C. M. Christianen, A. Larsen, G. Fytas, P. E. L. G. Leclère, A. P. H. J.

Schenning, E. W. Meijer, Angew. Chem., Int. Ed. 2010, 49, 3939-

3942.

[20] L. Bouteiller, O. Colombani, F. Lortie, P. Terech, J. Am. Chem. Soc. 2005, 127, 8893-8898.

[21] P. Jonkheijm, P. van der Schoot, A. P. H. J. Schenning, E. W. Meijer, Science 2006, 313, 80-83.

[22] J. Baram, H. Weissman, Y. Tidhar, I. Pinkas, B. Rybtchinski, Angew. Chem. 2014, 53, 4123-4126.

[23] F. Rodler, B. Schade, C. M. Jäger, S. Backes, F. Hampel, C. Böttcher, T. Clark, A. Hirsch, J. Am. Chem. Soc. 2015, 137, 33083317

[24] D. van der Zwaag, P. A. Pieters, P. A. Korevaar, A. J.

Markvoort, A. J. H. Spiering, T. F. A. de Greef, E. W. Meijer, J. Am. Chem. Soc. 2015, 137, 12677-12688.

[25] M. F. J. Mabesoone, A. J. Markvoort, M. Banno, T. Yamaguchi, F. Helmich, Y. Naito, E. Yashima, A. R. A. Palmans, E. W. Meijer, J. Am. Chem. Soc. 2018, 140, 7810-7819.

[26] A. Sorrenti, R. Rodriguez-Trujillo, D. B. Amabilino, J.

Puigmartí-Luis, J. Am. Chem. Soc. 2016, 138, 6920-6923.

[27] S. Ogi, V. Stepanenko, J. Thein, F. Würthner, J. Am. Chem. Soc. 2016, 138, 670-678.

[28] T. Fukui, S. Kawai, S. Fujinuma, Y. Matsushita, T. Yasuda, T. Sakurai, S. Seki, M. Takeuchi, K. Sugiyasu, Nat. Chem. 2016, 9, 493 499.

[29] E. E. Greciano, B. Matarranz, L. Sánchez, Angew. Chem. 2018, $57,4697-4701$.

[30] P. A. Korevaar, S. J. George, A. J. Markvoort, M. M. J.

Smulders, P. A. J. Hilbers, A. P. H. J. Schenning, T. F. A. De Greef, E W. Meijer, Nature 2012, 481, 492-496.

[31] P. A. Korevaar, T. F. A. de Greef, E. W. Meijer, Chem. Mater 2014, 26, 576-586.

[32] A. T. Haedler, S. C. J. Meskers, R. H. Zha, M. Kivala, H.-W. Schmidt, E. W. Meijer, J. Am. Chem. Soc. 2016, 138, 10539-10545. [33] K. Venkata Rao, D. Miyajima, A. Nihonyanagi, T. Aida, Nat. Chem. 2017, 9, 1133-1139. 
[34] T. Pinault, B. Isare, L. Bouteiller, ChemPhysChem 2006, 7, 816819.

[35] B. G. Alvarenga, M. Raynal, L. Bouteiller, E. Sabadini, Macromolecules 2017, 50, 6631-6636.

[36] H. Fenniri, B.-L. Deng, A. E. Ribbe, J. Am. Chem. Soc. 2002, 124, 11064-11072.

[37] N. J. Van Zee, B. Adelizzi, M. F. J. Mabesoone, X. Meng, A. Aloi, R. H. Zha, M. Lutz, I. A. W. Filot, A. R. A. Palmans, E. W. Meijer, Nature 2018, 558, 100-103.

[38] T. F. A. de Greef, M. M. L. Nieuwenhuizen, P. J. M. Stals, C. F. C. Fitie, A. R. A. Palmans, R. P. Sijbesma, E. W. Meijer, Chem. Commun. 2008, 4306-4308.

[39] M. A. J. Veld, D. Haveman, A. R. A. Palmans, E. W. Meijer, Soft Matter 2011, 7, 524-531.

[40] A. Desmarchelier, M. Raynal, P. Brocorens, N. Vanthuyne, L. Bouteiller, Chem. Commun. 2015, 51, 7397-7400.

[41] V. Ayzac, M. Raynal, B. Isare, J. Idé, P. Brocorens, R. Lazzaroni, T. Etienne, A. Monari, X. Assfeld, L. Bouteiller, PCCP 2017, 19, 32443-32450.

[42] M. Dirany, V. Ayzac, B. Isare, M. Raynal, L. Bouteiller,
Langmuir 2015, 31, 11443-11451.

[43] D. Demus, J. W. Goodby, G. W. Gray, H. W. Spiess, V. Vill, Handbook of Liquid Crystals, Wiley, Weinheim, 2011.

[44] The ordering of the assemblies is also confirmed by a weak birefringence of the solution (see Figure S6).

[45] G. A. Jeffrey, J. Mitra, J. Am. Chem. Soc. 1984, 106, 5546-5553.

[46] I. Rozas, I. Alkorta, J. Elguero, J. Phys. Chem. A 1998, 102, 9925-9932.

[47] R. D. Parra, H. Zeng, J. Zhu, C. Zheng, X. C. Zeng, B. Gong, Chem. Eur. J. 2001, 7, 4352-4357.

[48] C. Toniolo, G. M. Bonora, A. Bavoso, E. Benedetti, B. Di

Blasio, V. Pavone, C. Pedone, V. Barone, F. Lelj, M. T. Leplawy, et al., Biopolymers 1988, 27, 373-379.

[49] R. W. Newberry, R. T. Raines, Nat Chem Biol 2016, 12, 1084 1088 .

[50] T. Alfrey, A. Bartovics, H. Mark, J. Am. Chem. Soc. 1942, 64, $1557-1560$.

[51] A. Tessa ten Cate, R. P. Sijbesma, Macromol. Rapid Commun. 2002, 23, 1094-1112.

[52] K. F. Wissbrun, J. Rheol. 1981, 25, 619-662. 
